\title{
Discussion of the Risks and Risk Control of P2P in China
}

\author{
Xue Lei \\ School of Business Administration, South China University of Technology, Guangzhou, China \\ Email: Sharon_scut@163.com
}

Received 8 March 2016; accepted 17 April 2016; published 20 April 2016

Copyright (C) 2016 by author and Scientific Research Publishing Inc.

This work is licensed under the Creative Commons Attribution International License (CC BY). http://creativecommons.org/licenses/by/4.0/

(c) (i) Open Access

\begin{abstract}
As a kind of finance innovation for direct lending between individuals, P2P develops rapidly in recent ten years. However, while it is promoting China's economic development, various problems related to P2P network credit and loan are appearing gradually. If P2P wants to develop continuously, the core is to strengthen the risk management. Based on the analysis of the concept, model and positive significance of P2P network credit and loan, this paper mainly expounds the credit risks, information risks, operational risk, regulatory and legal risks and liquidity risk that P2P network credit and loan faces, and comes up with the solutions to these problems, for example, setting up the credit system, perfecting internal control as well as strengthening supervision and industrial self-regulation, combining big data technology. These present some new ideas of performing risks management for P2P.
\end{abstract}

\section{Keywords}

P2P, Risk Control

\section{Problem Introduction}

P2P (Peer-to-Peer) and loan refers to the direct lending activities between individuals without financial intermediaries, like a bank, with the network platform providing credit intermediation service as the medium [1]. P2P is a kind of Internet finance, an effective supplement to traditional finance, which is preferred by more and more medium and small investors and borrowers, as it is featured by covenant lite, convenience, rapidity and the hedge effectiveness of financial services license control. On November 1, 2015, A Research Report for P2P Micro-credit Market in the First Half of 2015 in China released by iiMedia Research indicated that, in the first half of 2014, the number of P2P loan platforms reached up to 1208, and by the first half of 2015, it had increased to 2180. But meanwhile, some negative information, such as "running tide" and "bankruptcy tide" follows one by 
one into the industry, which casts a shadow on the development of P2P. The officer from the China Banking Regulatory Commission confirms that from the establishment of this industry to July, 2014, there were actually 150 loan platforms running away and 6 - 7 for each month. The chaotic operation mode, and the risks due to the lack of relevant laws and supervision restrict the further development of P2P industry. How to effectively identify and manage P2P risks has been an urgent problem.

\section{Operation Model and Process and Positive Significance of P2P}

The typical operation model of P2P is that the debtor and creditor perform a free bidding and finally enter into debtor-creditor relationship, with a P2P company as the platform. The money lender gains the interest and bear risk; the money borrower repays the principal in the due time and the P2P company charges for intermediary service. In China, the P2P operation model can be divided roughly into pure online mode and online-and-offline binding mode [2]. The operation mode is as shown in Figure 1.

Firstly, P2P is featured with small loan and convenience, which fills the gap of traditional finance to some extent. It aims to present the inclusivity of financial service and continuously promote product innovation while cooperating with traditional finance, to better meet the diversified requirements of customers; secondly, P2P can facilitate the development of private capital to better serve the real economy. Meanwhile, it can greatly reduce the transaction cost of financial enterprises, raise the efficiency of capital allocation and improve the quality of financial service. In addition, P2P is also a double-edged sword. The multiple risks facing it have restricted its further development.

\section{Main Risks Facing P2P}

Based on the analysis of the P2P business process and environment, the author holds that the risk of P2P lies in the follow several aspects:

1) Credit risk

The credit appraisal system of P2P is incomplete. In traditional credit pattern, the bank has a large number of real data of the borrower and can minimize the information asymmetry degree during credit process. Therefore, the bank can be responsible for credit management, loan examination and so on [3]. While in P2P environment, taking into consideration of preventing customer loss, the P2P platform will only reveal part of the borrower's information. In addition, some motivated borrowers invent their identities or financial position through various

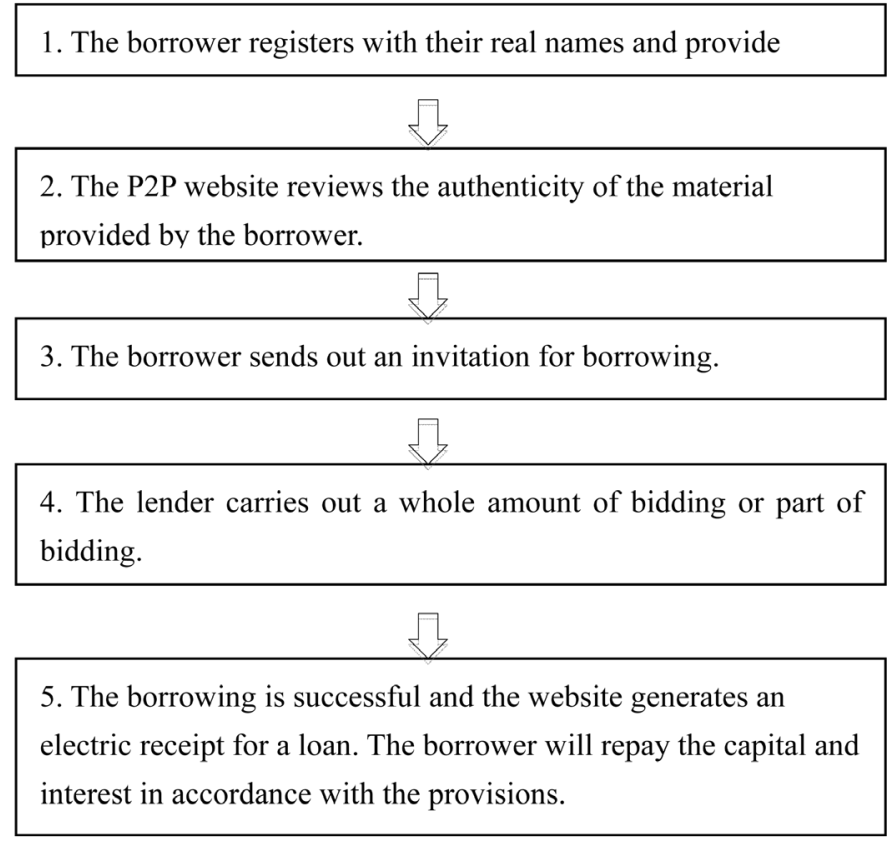

Figure 1. Flow chart of the operation mode of P2P. 
channels, and they even take advantage of the loophole of information asymmetry in P2P companies. For example, the Ants Moving, who registered and borrowed money in many P2P companies, raised an enormous sum of money rapidly, which not only break the law, but also greatly endanger the lender's fund safety.

2) Risk of information technology

On one hand, the influence of network information technology on the P2P, established on the basis of Internet, is much greater than that of traditional credit. However, the current situation of the P2P without supervision and threshold in our country causes the emergence of a great number of P2P platforms, including the grass-roots entrepreneurs who don't understand Internet technology and financial risk. And the information system of P2P platform is not perfect, full of loopholes and once it is attacked by hackers, the overall business process will break down. The safety of websites cannot be guaranteed.

On the other hand, when the borrowers borrow money on P2P platform, they have to fill in detailed personal information. Sometimes they are also required to fill in some related information of their relatives and friends in order to provide identification. However, with the increasing popularity of the P2P, once the huge information database is stolen by lawbreakers or disclosure of information is caused due to management flaws, the P2P will face great information risk, which can cause a great damage to the users.

3) Operation risk

On one hand, as an emerging industry, the P2P with low threshold, lack of legislation and supervision, does not put forward to the mandatory requirement for management qualifications and professional qualities of the operators. These all cause that the staff in P2P companies are of varying quality and many credit officers cannot make accurate judgments about the credit and operation situation of the borrowers, which enlarges the information asymmetry before loaning and makes it more difficult to manage the after-loaning risk. In addition, the reference value of the auditing results of the credit risk of the borrowers acquired by credit officers is actually low, which is likely to mislead the decisions made by the investors.

On the other hand, at present, there is no stipulation on the person managing the terminal account and many P2P companies manage the loans themselves. Once the internal controls, governance mechanism or information technology system in P2P company fail, the risk of illegal diversion of funds is likely to happen. In addition, this method of concentrating cash first and then looking for borrowers will make the capital gathered in P2P companies, which will generate a capital pool. It is nothing else but luring money in a disguised form. Thus, the P2P companies will evolve into illegal financial institutions [4].

4) Regulatory and legal risks

On one hand, though P2P positions itself as an information intermediary agency, the funding operation of the P2P provides it with some attributes of financial institutions. The administration for P2P hasn't explicitly stipulated that the China Banking Regulatory Commission, the People's Bank of China and other institutions all cannot control the capital flow and operation situation, which makes the P2P industry present a spontaneous and out-of-order state as a whole.

On the hand, up to now there still hasn't a set of laws for P2P industry. Many P2P companies are on the margins of the law and they even break the law. For example, through repackaging borrowing demand into financial products, the P2P companies absorb the investors' capital, thus generating a capital pool within the companies. They also perform illegal fund-raising by releasing false borrowing targets. In addition, the Ponzi scheme of "Borrowing for Repaying" mentioned above also belongs to illegal financing. However, currently, the above problems still cannot be well defined and restricted in legal form. An awkward situation with no suitable legislation, combined with the loss of regulation, causes disorderly operations of the P2P industry with a great number of problems. Meanwhile, the interest of lenders cannot be protected effectively, facing significant risks.

5) Liquidity risk

The bigger the P2P company, the bigger the liquidity risk. Different from banks and other financial institutions with regulatory endorsement, P2P industry is still in a fragmented situation due to lack of supervision. Once larger financing project is exposed to payment risk or faces systematic risk, the investors run will be caused as the P2P platform cannot "cope with the problems". Furthermore, part of P2P companies guarantees the principal of lender. However, the rate of bad account of $\mathrm{P} 2 \mathrm{P}$ companies is generally high. Once the amount guaranteed by P2P companies exceeds their solvency, the companies will break down due to liquidity problem.

\section{Risk Management and Control of P2P}

As the business mode of establishing debtor-creditor relationship directly between the borrowers and lenders, 
the core of P2P business lies in its risk pricing capability. Only by managing and controlling various risks of $\mathrm{P} 2 \mathrm{P}$, can the P2P companies avoid all kinds of unnecessary lost during the development of P2P, protect the rights of lenders effectively to enhance the confidence of the lenders and make P2P institutions gain through reducing credit risk instead of increasing borrowing rates viciously.

1) Make rules and laws, establish a regulatory mechanism and standardize the P2P credit business

a) Formulate and promulgate the special laws for network finance or P2P, clarify the intermediary nature of P2P platform, prohibit the P2P platform from guaranteeing and setting up a capital pool by law, define the threshold between the lawful operation of P2P and illegal absorbing public funds to make P2P operate lawfully.

b) Establish and perfect the supervision mechanism of P2P, clarify the supervision identity, fulfill the supervisory responsibilities in various aspects during the whole process of P2P credit business. Taking "clear positioning", "no touching money", having a threshold", "transparency focusing" "strengthening self-discipline" as supervision direction, manage and control the operation mode, business area, risks and interest rate management, identify the responsibilities of all parties, strictly prohibit P2P platform providing offering for security, raising funds for self financing and setting up capital pool, strengthen the supervision of the third party related to capital, lay down concrete platform user information security assurance and remove the unqualified platform in a timely manner to ensure orderly business practices.

2) Perfect the construction of credit reporting system and depend on credit reporting system to conduct risk evaluation

a) Set up credit grading index system based on qualitative and quantitative analysis, establish credit standing platform or credit investigation system shared by P2P industry, develop unified credit evaluation standard and push for much tighter credit grading index system. At initial stage, mainly concentrate on qualitative analysis and gradually focus on quantitative analysis after the completion of the sample data, use big data technology, strengthen credit system through data mining, build data risk control model and apply it to decision engine and assessing card system, so as to improve the degree of decision automation, reduce the high cost of artificial auditing, solve the problem caused by inconsistent artificial auditing standard. Thus, the credit of borrowers can be rated in accordance with loaning information to make the borrower have a good understanding of the risks of the loan and reduce credit risk.

b) Boost the integrating with external credit reporting system, especially the credit reporting system of the Central Bank, access the credit reporting system of the Central Bank based on regions and procedures and unify credit system. The credit reporting data of the Central Bank and the operation information and material of the third-party enterprises can be adopted to rate the credit of the middle and small-sized enterprises applying for loan. Moreover, authenticity and degree of risk of financial information of individual borrowers can be evaluated through combining the individual credit reporting system of the Central Bank with the network credit data of P2P to change the situation of irrationally choosing lending projects by investors.

c) Establish and perfect credit rewarding and punishing system and promote blacklist exposure system. Once the borrowers lose credit, they will be added to the blacklist. Meanwhile, enlarge the degree of punishment for losing credit and breaking a contract and increase the cost of discredit of enterprises and individuals so as to promote the sound development of P2P [1].

3) Standardize the operating process of the P2P platform, perfect internal control system and improve the personnel quality

a) P2P companies shall operate legally following related rules, set up special risk-control departments or groups and establish a complete risk control system to effectively prevent and control the companies' risk. Meanwhile, the companies shall establish strict and perfect rules and regulations and work process, perfect internal operating process to make sure of strict examination before loan, close tracking during loan and strengthening the management after loan, perfect the loan examination system of the P2P, check the loan amount, interest, duration, use of funds, credit and other factors, actively cooperate with regulators and submit data report to them regularly.

b) Provide specialized training for employees regularly. The training of relational knowledge system shall be intensified to make the employees digest it, identify the risk of financing projects with all-round vision and from several different angles, find exactly the risk point of financing projects and control it and continuously improve the level of refining risk control and the information controlling ability. At the same time, the moral quality of staff shall also be improved, through strengthening the disciplinary punishment for rule-breaking 
operations of employees to prevent the ethics risks and the resulting system risk.

c) Through introducing advanced technology, set up the security information system for P2P websites, improve the operating efficiency of the platform and protect users' capital and personal information safety.

4) Strengthen cooperation, establish industry self-discipline organizations and hold back the chaotic phenomena during industry development

The P2P industry shall establish industry self-discipline organizations or associations, issue industry standard and regulations, strengthen industry standardization and take on moral supervision through consultation. In addition, the industry shall also expose the methods of interest calculation and create interest rate pricing methods to take severe measures against the high-interest speculative actions, through setting maximum loan amount, and establishing a blacklist exchange and exposure system, to constrain the P2P effectively, promote the standardization of carrying out P2P, improve the protection of borrowers' rights and make the industry self-discipline organization constrain P2P operation and be a complement to the supervision.

\section{Conclusions}

In this paper, there are still some limitations. It only studied the risks and control issues of China's P2P, which offered some reference to P2P in China. However, the comprehensive and general global P2P issues are overlooked, as well as the advantages and positive influence of P2P. Thus, the follow-up studies related to P2P and Internet financial problems can be performed from other perspectives. In addition, some more interesting studies can be made to trace the source of P2P.

There is nothing more to be said about the contributions that the P2P, as a kind of financial innovation, makes to solve the financing difficulties which the middle and small-sized enterprises and individuals face. But the high risks during its development and the frequent occurrence of negative news also discourage a few people from enjoying it. The sound development of the P2P industry is closely related to the effective management and control of risk, by which the risks of P2P industry can be reduced to make it run smoothly and maintain the vitality of folk finance at the same time. Thus, the financial inclusion of P2P can be given a full play.

\section{References}

[1] Heng, S., Meyer, T. and Stobbe, A. (2007) Implications of Web 2.0 for Financial Institutions: Be a Driver, Not a Passenger.

[2] Luo, M.X. (2014) P2P Three Patterns of Net Credit-Online Pattern and Binding Pattern of Online and Offline, July $11^{\text {th }}$, 2014. http://stock.sohu.com/20140711/n402104734.shtml

[3] Haolyy: The Combination between Credit Factory and Financial Big Data Can Improve the P2P Risk Management Effectively. http://finance.china.com/fin/lc/201409/26/2902036.html

[4] He, X.L. (2013) The Innovation of Microfinance: P2P Net Credit Research. Chinese \& Foreign Entrepreneurs, 47-49. 